\title{
Prediction of greenhouse gas emission from municipal solid waste for South Korea
}

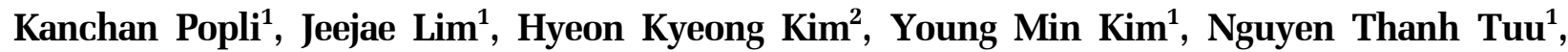 \\ Seungdo $\mathrm{Kim}^{1^{\dagger}}$
}

${ }^{1}$ Department of Environmental Science and Biotechnology, Hallym University, Chuncheon, South Korea

${ }^{2}$ Division of Information and Telecommunications, Hanshin University, Seoul, South Korea

\begin{abstract}
This study is proposing a System Dynamics Model for estimating Greenhouse Gas (GHG) emission from treating Municipal Solid Waste (MSW) in South Korea for years 2000 to 2030. The government of country decided to decrease the total GHG emission from waste sector in 2030 as per Business-as-usual level. In context, four scenarios are generated to predict GHG emission from treating the MSW with three processes i.e., landfill, incineration and recycling. For prior step, MSW generation rate is projected for present and future case using population and waste generation per capita data. It is found that population and total MSW are directly correlated. The total population will increase to 56.27 million and total MSW will be 21.59 million tons in 2030. The methods for estimating GHG emission from landfill, incineration and recycling are adopted from IPCC, 2006 guidelines. The study indicates that Scenario 2 is best to adopt for decreasing the total GHG emission in future where recycling waste is increased to $75 \%$ and landfill waste is decreased to $7.6 \%$. Lastly, it is concluded that choosing proper method for treating the MSW in country can result into savings of GHG emission.
\end{abstract}

Keywords: Greenhouse gases, Municipal solid waste, System dynamics modelling, South Korea

\section{Introduction}

The emission of greenhouse gases (GHGs) from improper management of generated municipal solid waste (MSW) is one of the biggest concerns for the developing as well as for the developed countries. South Korea being a developed nation determined to reduce the GHG emission by $23 \%$ from the waste sector by 2030 as per business as usual level [1]. Since 1990's, Korean society is emphasizing on recycling and reusing of MSW to achieve a zero waste society in order to treat the tremendously increasing amount of MSW in an environmental and economical friendly manner. Before 1990s, Korean society adopted the policy of safe and clean environment and expanded the waste treatment facilities. Later in era of 1990s, the increasing demand of reducing the pollution from solid waste treatment led the society to shift their policy goals towards the reduction of waste by reusing or recycling and thus to achieve zero waste society [2]. Various policy tools were introduced to implement the goal of reducing waste to large extent such as: Volume-based waste fee system, Enforced Recycling through deposit system and assistance programs for recycling industries [3]. This work is performed to study the present policy and goal of the government that to reduce the GHG emission from MSW by increasing recycling rate in future. The primary step is to predict the total MSW and total GHG emission from MSW from disposal options for present and future case. Most of the work shows GHG savings from recycling process because recycling of products save energy. It is important for policymakers to better understand the impact of disposal options for management of MSW. Thus, there is need to evaluate GHG emission from recycling process.

Earlier, various studies were performed by implicating the government policies in managing the MSW and to predict the emission of GHG in future with or without using system dynamics modelling (SDM). For example, the management of solid waste with policy analysis has been performed [4], the emission of methane from MSW with policy implied by the government was calculated [5]
This is an Open Access article distributed under the terms of the Creative Commons Attribution Non-Commercial License (http://creativecommons.org/licenses/by-nc/3.0/) which permits unrestricted non-commercial use, distribution, and reproduction in any medium, provided the original work is properly cited.
Received January 15, 2019 Accepted July 01, 2019

${ }^{\dagger}$ Corresponding author

Email: sdkim@hallym.ac.kr

Tel: +82-10-6340-1536 Fax: +82-33-242-1536

Copyright (C) 2020 Korean Society of Environmental Engineers 
(MoE, 2009) shows policies for sustainable management in SK [6], Ryu studied to reduce GHG emission from sustainable MSW management and utilizing waste to energy in case for SK [7]. It has been found that the SDM approaches were applied for the management of solid waste and to estimate GHG emission in many scenarios [8], as example, evaluation of the GHG emission and the energy recovery from MSW with the alternative treatment methods was performed by SDM approach in Vietnam [9]. In another context, the emission of GHG for recycling of MSW by SDM was performed in Indonesia [10].

The study aims to observe the behavior of policy made in more realistic view by government in order to reduce the final GHG emission from waste sector. The policy of increasing recycling waste and dumping minimum waste to landfill under "zero waste policy" is adopted for SK [11]. Initially, total MSW is predicted from year 2000 to 2030 with help of system dynamics (SD) modeling software using VENSIM. Secondly, total GHG emission is evaluated by adding GHG emission from disposal of waste from three processes i.e., landfill, incineration and recycling. With giving more priority of increasing recycling waste in future to reduce GHG emission or to save GHG emission, four scenarios are generated. The drawback here is lack of availability of data for recycling GHG emission factor and GHG saving factors from recycling for SK. The study assumes that waste generation follows same trend for SK for present as well as for future situation.

\section{Methods}

\subsection{Preparation of System Dynamic Model}

A system dynamic model is prepared with help of software named as "VENSIM". The SDM is done to predict the MSW generation amount and thus total GHG emission from every process involved for treatment. The running time is for thirty years starting from 2000. SD is a system analysis technique and computer dependent approach to study any system. The initial step is to make causal loop diagram (CLD). CLD gives an overview to the important parameters which are involved in any system. The causal loop diagram of MSW management involved in this study is presented with Fig. 1.

The involved parameters are connected with arrows, the positive and negative sign on arrows presents the direct and indirect relation between two parameters, respectively [12]. The parameters are called 'variables' whose value is changed with time. The 'constants' have fixed value. The CLD is then designed into a stock and flow diagram as shown with Fig. 2. A 'stock' is a parameter which build-up and diminishes over time and 'the rate of change' in a stock quantity is shown by flow. To study the qualitative and the quantitative relationship between the 'stocks' and the 'flows' parameters; the parameters are provided the mathematical equations.

The study is divided into two main segments where first section showing present and future trends in MSW generation. The second section has three subsections. The subsections include present and future calculation of: 1) GHG emissions from disposal of

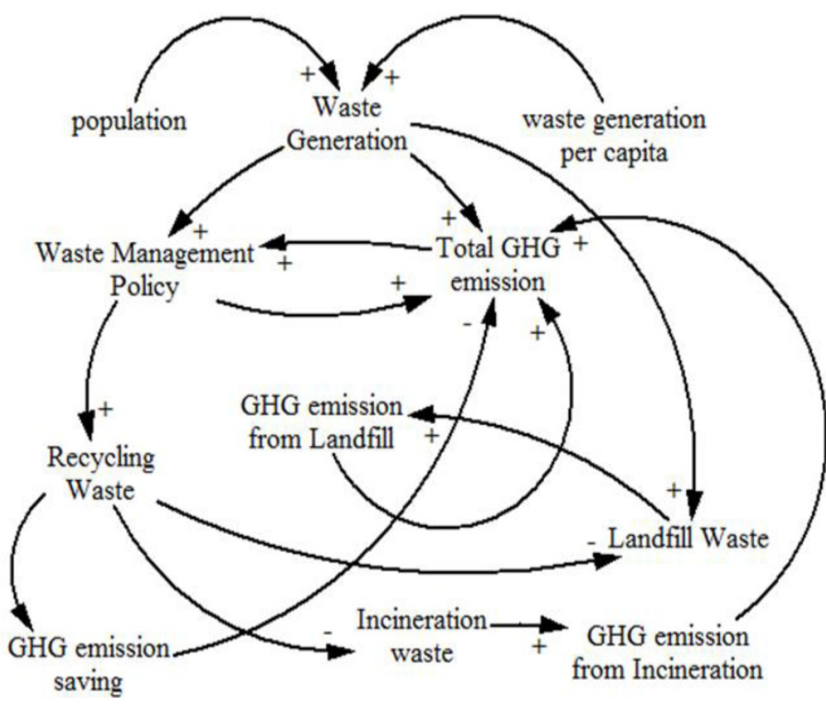

Fig. 1. Causal loop diagram of MSW. The positive and negative sign on arrows presents the direct and indirect relation between two parameters, respectively.

MSW into landfill; 2) GHG emission from treating MSW with incineration; and 3) GHG emission and GHG savings from recycling of MSW.

\subsubsection{Calculation of total MSW generation}

The MSW in SK includes standard plastic garbage bags, food waste, recyclable waste including glass bottles, bulky waste (furniture/appliances), business residential waste and other waste except industrial wastes [13]. The increase in economy, affluences and high living standards give-rise to the MSW generation [14]. Hence, the study involves two main parameters for calculating total MSW i.e., population and the waste generation per capita. The population growth rate is involved to determine the future population in SK. Similarly, the trend in growth rate of waste generation per capita is considered to estimate the waste generation per capita in future. The following equation is used to calculate total MSW generation:

Total MSW $=$ population $\times$ waste generation per capita

\subsubsection{Calculation of total GHG emission from total MSW}

\subsubsection{The GHG emission from the landfill section}

The landfill gas is the result of anaerobic decomposition of solid waste. It consists of $50 \%$ of methane and $50 \%$ of carbon dioxide with some trace elements $(<1 \%)$ of nitrogen, oxygen, hydrogen sulphide, hydrogen and non-methane organic compounds (NMOCs) [15]. The amount of generation of landfill gas depends on the quantity and composition of the waste. The amount of gas generating from waste dumped to landfill varies with different conditions like temperature, moisture, nutrient source available to microbes undergoing the biochemical activity [16]. Methane is 25 times more potent GHG than carbon dioxide from landfill. Hence, this study involves the calculation of methane gas using TIER II method from IPCC guidelines [17] as shown with Eq. (2). 


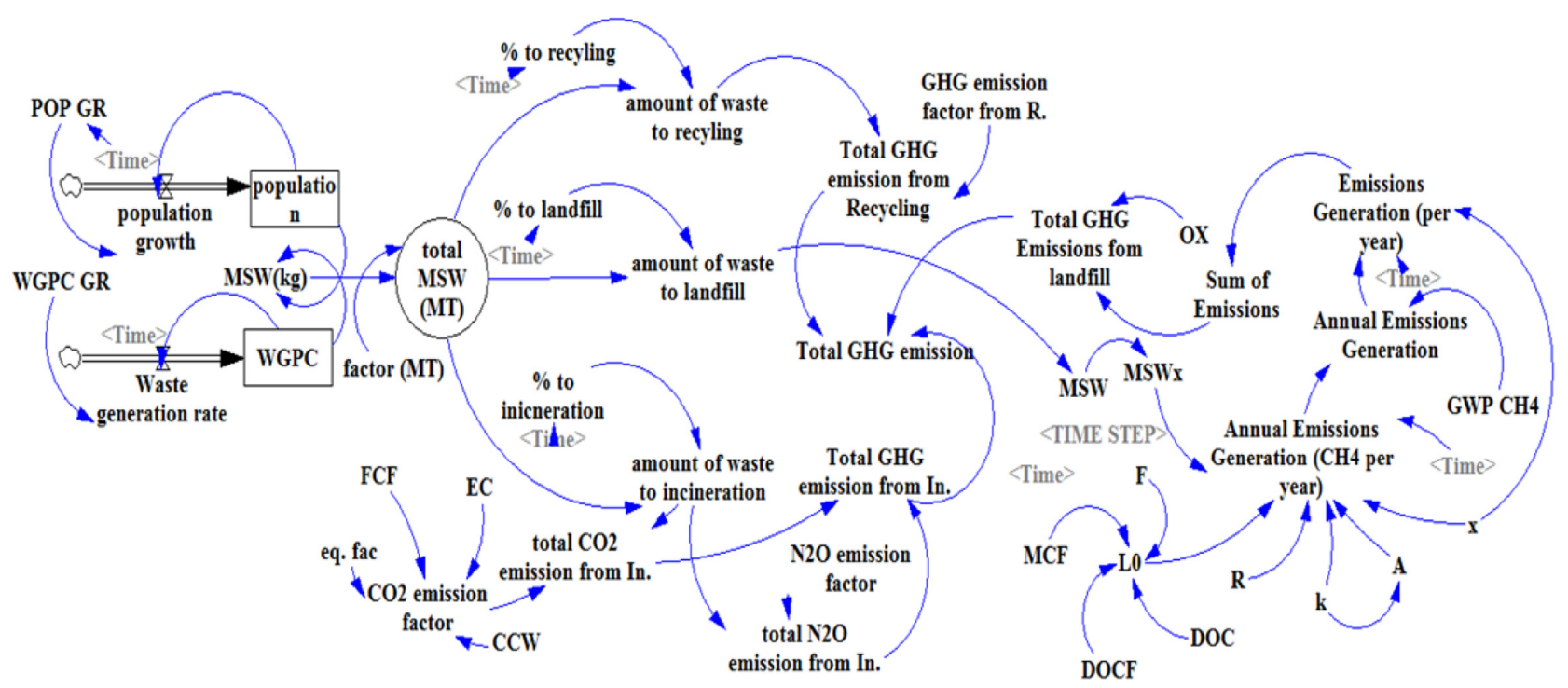

Fig. 2. System dynamics modelling of MSW.

$$
\begin{aligned}
E= & \sum_{x}\left[\left(A \times k \times \operatorname{MSW}(x) \times \operatorname{Lo}(x) \times e^{-k(t-x)}\right)-R\right] \\
& \times(1-O X)
\end{aligned}
$$

where,

$\mathrm{E}=$ annual $\mathrm{CH}_{4}$ emissions (million tons/year)

$\mathrm{A}=\left(\frac{1-\mathrm{e}^{-\mathrm{k}}}{\mathrm{k}}\right):$ Normalization factor

$\mathrm{t}$ : the year in which emissions are calculated

$\mathrm{x}$ : waste landfill year associated with the generation of $\mathrm{CH}_{4}$ (year)

$\mathrm{k}: \mathrm{CH}_{4}$ rate constant

$\operatorname{MSW}(\mathrm{x})$ : total amount of solid waste buried in the year $\mathrm{x}$ Lo : potential amount of Methane

$\mathrm{R}: \mathrm{CH}_{4}$ recovery quantity

$\mathrm{OX}: \mathrm{CH}_{4}$ oxidation rate

The study assumes that methane recovery from landfill is zero. The potential amount of methane (Lo) involved in Eq. (2) is calculated with following Eq. (3):

$$
\mathrm{Lo}=\mathrm{MCF} \times \mathrm{DOC} \times \mathrm{DOCf} \times \mathrm{F} \times\left(\frac{16}{12}\right)
$$

where,

Lo : Potential amount of $\mathrm{CH}_{4}$

MCF : Methane Correction Factor

DOC : Decomposable Organic Carbon

DOCf : percentage of organic carbon in anaerobically decomposable waste

$\mathrm{F} \quad$ : $\mathrm{CH}_{4}$ component ratio in Landfill gas

The value of parameters used in Eq. (2) and Eq. (3) are given as: $\mathrm{k}$ is $0.05, \mathrm{~F}$ is $0.5629, \mathrm{MCF}$ is $1.0, \mathrm{DOC}$ is 0.09 , DOCf is 0.5 and OX is 0.1 [18].

\subsubsection{GHG emission from incineration}

The burning of waste mainly generates two types of gas: Carbon dioxide $\left(\mathrm{CO}_{2}\right)$ and nitrous oxide $\left(\mathrm{N}_{2} \mathrm{O}\right)$ with some traces of ammonia $\left(\mathrm{NH}_{3}\right)$, oxides of nitrogen $(\mathrm{NOx})$ and organic carbon $\mathrm{C}$ or total carbon [19]. The study involves calculation of: 1) carbon dioxide emission and 2) nitrous oxide emission from incineration process. The total carbon dioxide emission and nitrous oxide emission is evaluated with following Eq. (4), (5) and (6), respectively.

$$
\mathrm{E}=\Sigma \mathrm{EF} \times \mathrm{A}
$$

where,

E : Carbon dioxide emission from Incineration (Million ton $\mathrm{CO}_{2}$ equivalent/year)

$\mathrm{EF}$ : Emission factor of $\mathrm{CO}_{2}$ (Million ton $\mathrm{CO}_{2}$ eq. / Million ton of waste)

A : Activity Data (Million ton/year)

The emission factor used in Eq. (4) is calculated with Eq. (5).

$\mathrm{CO}_{2}$ emission factor $=\sum(\mathrm{CCWi} \times \mathrm{FCFi} \times \mathrm{ECi}) \times\left(\frac{44}{12}\right)(5)$

where,

CCWi : Carbon content by type of waste

FCFi : Fossil carbon content by type of waste

ECi : Incineration efficiency by type of waste

The value for parameters used in Eq. (5) are given as CCWi is 0.05 , FCFi is 0.5629 and ECi is1.0 [20].

$$
\mathrm{Ei}=\mathrm{Ai} \times \mathrm{EFi}
$$

where,

Ei : $\mathrm{N}_{2} \mathrm{O}$ emission due to Incineration by type of waste (Million 
ton $\mathrm{CO}_{2}$ eq./year)

$\mathrm{Ai}$ : Activity data (Million ton/year)

EFi : $\mathrm{N}_{2} \mathrm{O}$ emission factor by type of waste $=0.017$ million ton $\mathrm{CO}_{2}$ equivalent (eq.)/million ton of waste [20] presents the emission factor for nitrous oxide from MSW. The value of emission factor comes by including global warming potential of nitrous oxide i.e., 298.

\subsubsection{GHG emission from recycling}

The GHG emission from recycling process follows Eq. (7). The data for amount of recyclable waste is adopted from MoE [21]. Turner et al. [22] calculated the GHG emission factors and GHG savings from recycling for source segregated waste waste, which is adopted same for SK [22]. SK does separation of waste but this study assumes that country produces mainly four types of recyclable waste i.e., paper, plastic, metal and glass in equal and mixed proportions. Hence, the study uses the average of emission factors for four type of waste.

$$
\mathrm{E}=\mathrm{MSW}(\mathrm{r}) \times \mathrm{EF}
$$

where,

E : Emission from Recycling

MSW(r): MSW going to recycling

$\mathrm{EF}$ : emission factor

\section{Scenario Generation}

The government of Seoul has decided to increase the rate of recycling of household waste up to $75 \%$ in 2030 with minimum waste disposal to landfill [11]. National Waste Statistics Survey of Korea mentioned that the minimum amount of non-recyclable and non-combustible waste in SK is $7.6 \%$ that can end up to landfill [20]. It is assumed that increasing the amount of recyclable waste would decrease the burden on landfill and incineration process. In context, the study is performed to observe the behavior of real policy view with help of SDM. Four scenarios are prepared to see the best case to observe final GHG emission by increasing recycling amount in future.

- Baseline: This scenario is simulated with current situation of disposal of waste to landfill, incineration and recycling by using "GHG emission factor from recycling".

- Baseline 1: This scenario is simulated by including "GHG savings factor from recycling” with current situation of waste disposal to landfill, incineration and recycling.

- Scenario 1: This scenario is simulated with including ratio of waste going to landfill as $7.65 \%$ of total MSW in 2030 and recyclable waste as $75 \%$ of total MSW with using "GHG emission from recycling".

- Scenario 2: The scenario includes that total amount of waste going to landfill in 2030 will be $7.6 \%$ of total MSW and recyclable waste will be $75 \%$ of total MSW by including "GHG saving factor from recycling process".

Table 1 shows the current situation of disposal of MSW to landfill, recycling and incineration.

Table 1. Amount of Waste to Landfill, Incineration and Recycling (2000 to 2014)

\begin{tabular}{lccc}
\hline Year & Landfill & Incineration & Recycling \\
\hline 2000 & 43.98 & 14.49 & 41.53 \\
2001 & 43.14 & 13.56 & 43.30 \\
2002 & 41.53 & 14.49 & 43.98 \\
2003 & 40.31 & 14.48 & 45.21 \\
2004 & 36.38 & 14.45 & 49.17 \\
2005 & 27.69 & 16.02 & 56.29 \\
2006 & 25.76 & 17.01 & 57.23 \\
2007 & 23.51 & 18.89 & 57.60 \\
2008 & 19.87 & 20.33 & 59.80 \\
2009 & 20.25 & 18.60 & 61.14 \\
2010 & 21.58 & 17.89 & 60.52 \\
2011 & 23.71 & 17.15 & 59.14 \\
2012 & 25.79 & 15.72 & 58.50 \\
2013 & 25.31 & 15.62 & 59.07 \\
2014 & 25.34 & 15.65 & 59.01 \\
\hline
\end{tabular}

Source: Ministry of Environment, Korea (2017)

\section{Results, Validation and Discussion}

GHG-emission should be controlled in the waste-treatment processes because it causes environmental pollution and plenty of ill-effects. The improper MSW management can increase GHG emission in surroundings. The following results are obtained with prediction of MSW from 2000 to 2030 for SK. The scenarios are then prepared and simulated with help of SD software which are given in detail as follows:

\subsection{Prediction of the Inter-relating Factors by Casual-loop Diagram and Scenarios Development}

SD models delineate the complexity between different interrelated factors. It predicts communication and identifies the feedbacks among them with an enhancement of the decision making policies in different scenarios [8]. The casual loop diagram, formed here, is important for showing the cause and effect changes between the different variables (Fig. 1 and 2). Within different methods available, the SDM has distinctive advantages as it can predict the future trends, study the system characteristics and find the effective ways to solve problems [23]. We used the real data of the waste going for treatment to landfill, incineration and recycling. Further, from the year 2015 until 2030 shows the simulated results for each case. Here, four scenarios are proposed to show change in final GHG emission in respect of choosing emission factor from recycling process and GHG savings from recycling process.

\subsection{Total MSW for SK from 2000 to 2030}

The study is initiated with calculation of total MSW in SK. It 
includes two parameters i.e. population and waste generation per capita. To run the baseline scenario, 'population growth rate' (POP GR) data is adopted from World Bank from years 2000 to 2014 and 'waste generation per capita growth rate' (WGPC GR) data is adopted from Ministry of Environment, Korea. Population and waste generation per capita are stocks, depending on growth rate. The initial value for population is population of Korea in 2000 i.e., 47.01 million people. The value of WGPC GR is average value of waste generation growth rate from years 2000 to 2014 . The initial value of WGPC (waste generation per capita) is $1.02 \mathrm{~kg}$. The predicted value of total MSW is 17.5 million ton (Mt) in year 2000. The MSW in SK is increasing with increasing population and increasing waste generation per capita with time. The population of SK in 2030 will reach to 56.27 million which is comparable to population data already predicted for Korea [24]. It is found that total MSW generation will reach to $21.59 \mathrm{Mt}$ in 2030 as shown in Fig. 3.

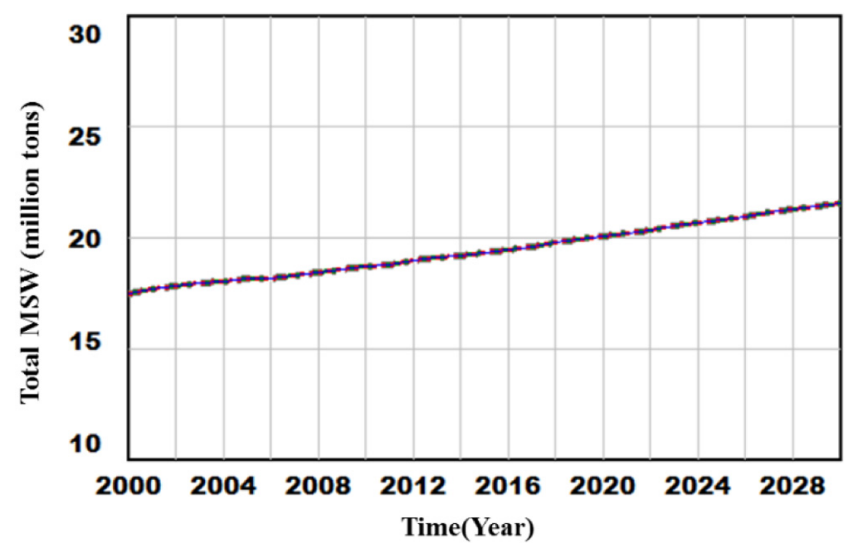

Fig. 3. Total MSW in SK (2000-2030).

This signifies that one person will generate $1.05 \mathrm{~kg}$ of waste per day in year 2030. World Bank report shows predicted waste generation per capita per day for high income countries to be 1.71 in 2030 [25]. SK is categorized under high-income country part of East Asia and Pacific Region. The Report also predicted that countries under this region will generate $0.68 \mathrm{~kg}$ of waste per person per day in 2030. World Bank report predicts waste generation per capita based on population and GDP. This study uses population and waste generation per capita for predicting waste by per person in per day. Thus, model does justification with the predicted number.

\subsection{Total Waste and GHG Emission from Three Processes: Landfill, Incineration and Recycling}

\subsubsection{GHG emission from landfill}

Fig. 4 presents total landfill waste and total GHG emission from landfill for SK. The GHG emission from landfill is calculated by using TIERII approach from IPCC guidelines [17]. The amount of waste disposed to landfill is important factor to decide total GHG emission from landfill sites. 'Baseline and Baseline1' follows present trend of waste going to landfill and shows simulated results from 2000 to 2014. 'Scenario1 and Scenario 2' results are obtained when amount of waste disposed to landfill is assumed to be $7.6 \%$

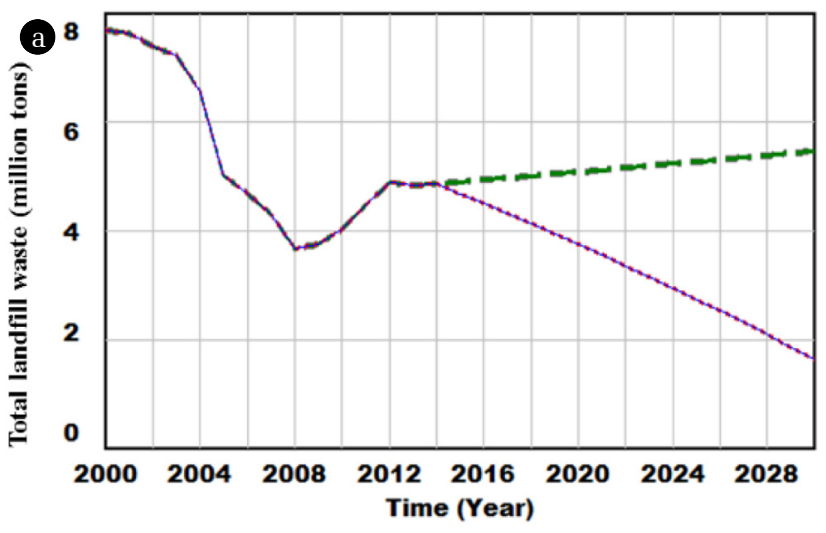

amount of waste to landfill : Scenario2

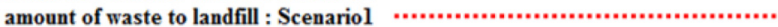
amount of waste to landfill : Baseline -----------

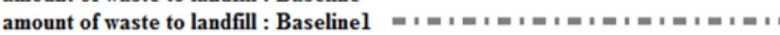

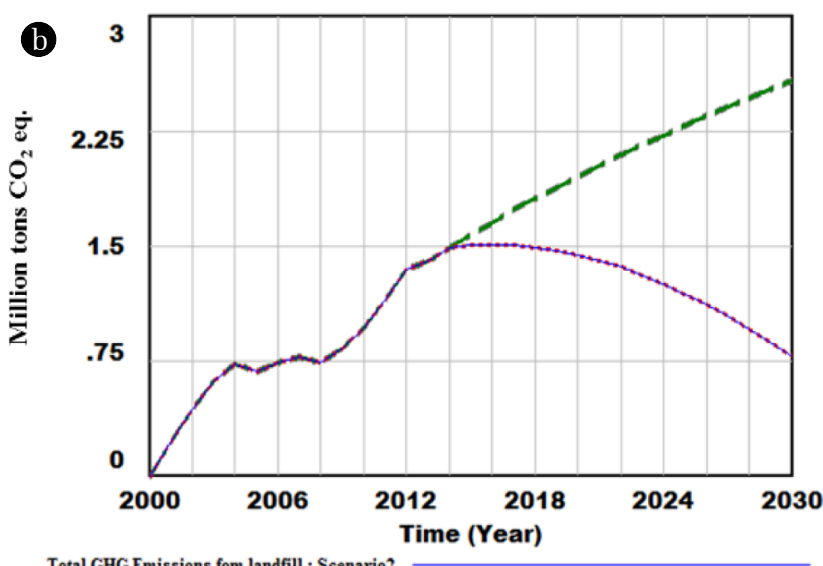

Total GHG Emissions fom landfill : Scenario 2

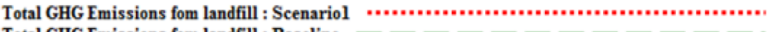

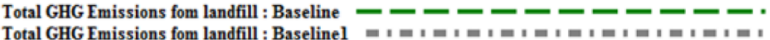

Fig. 4. Total landfill waste and Total GHG emission from landfill in SK (2000 to 2030).

in 2030. The waste disposal to landfill in year 2000 is 7.697 Mt. Baseline and Baseline1 simulated results shows that there will be decreasing pattern in landfill waste in 2030. 5.47 million tons of MSW will end up into landfill in baseline and baseline1 scenario. Sceario1 and Scenario 2 are showing that there will be huge decrease in landfill waste after adoption of zero waste policy. When the minimum amount of non-combustible and non-recyclable waste will be disposed to landfill, it will remain to $1.641 \mathrm{Mt}$ of total MSW. The study assumes that factors affecting landfill gas will remain same with age of landfill. The factors that may affect landfill gas are temperature, moisture, available oxygen etc. It has been observed that decreasing waste disposal to landfill has decreased the GHG emission from landfill. The GHG emission from landfill for baseline and baseline1 is predicted as 2.58 million ton $\mathrm{CO}_{2}$ equivalent ( $\mathrm{Mt} \mathrm{CO}_{2}$ eq.). The Scenario1 and Scenario 2 is showing

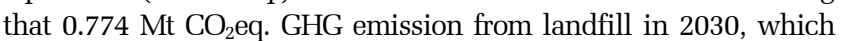
is quite a low number. The adoption of "zero waste policy" resulted into conclusion that lessening the burden of landfill would lessen the burden on environment. As landfill have environmental consequences due to production of leachate and gases that are harmful 
to human and natural systems [26]. There is zero emission in year 2000 as study assumes that life of landfill starts from year 2000 .

\subsubsection{GHG emission from Incineration process.}

The GHG emission from Incineration process is shown with Fig. 5. The total GHG emission is resultant of carbon dioxide emission and nitrous oxide emission from burning of MSW. The finding of emissions is based on formula adopted from National Inventory Report of Korea. It includes emission factors for each gas. The activity data for incineration waste is adopted from MoE. As shown in Fig. 5, there is hike in amount of incineration waste from year 2005 to 2008 due to adoption of "No disposal of food waste to landfill" policy by Korean government which has increased the burden on incineration plant [27]. The treatment option for food waste has gradually shifted from burning to recycling with composting. Thus, the amount of incineration has gradually decreased again with time. Eq. (6) and (7) shows direct relation of amount of emission for carbon dioxide and nitrous oxide. Thus, the amount of waste to incineration process and GHG emission shows similar increasing and decreasing pattern. The GHG emission

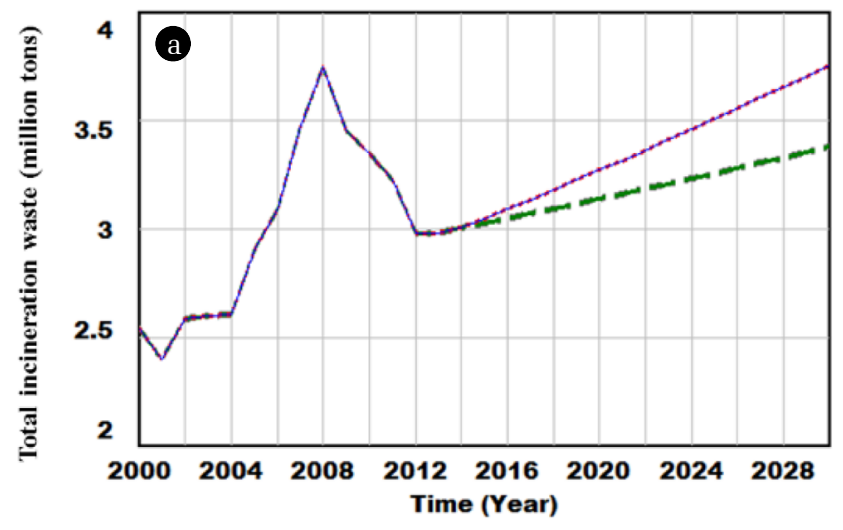

amount of waste to incineration : Scenario 2

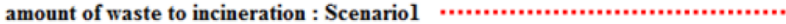
amount of waste to incineration : Baseline ----------

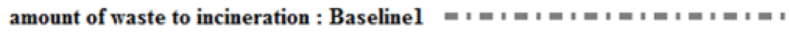

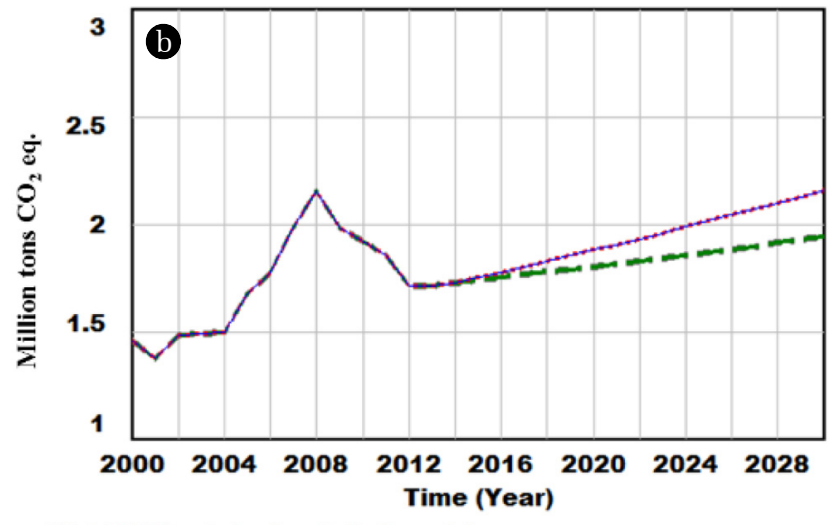

"Total GHG emission from In." : Scenario2

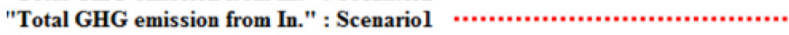

"Total GHG emission from In." : Baseline - - - - - -

"Total GHG emission from In." : Baselinel $=1=1+$ '

Fig. 5. Total incineration waste and total $\mathrm{GHG}$ emission from incineration process in SK (2000 to 2030). from incineration process is observed to be $1.94 \mathrm{Mt} \mathrm{CO}_{2}$ eq. in 2030 for 'Scenario1 and Scenario2'. The GHG emission in 'baseline and baseline1' is observed to be $2.157 \mathrm{Mt} \mathrm{CO}_{2}$ eq. in 2030 due to increase in amount of waste.

\subsubsection{GHG emission from recycling.}

Fig. 6 shows GHG emission from recycling. The emission factor from recycling is adopted from earlier study [22]. This work is performed to evaluate GHG emission from recycling and GHG emission savings from recycling. For calculating GHG emission from recycling; the value of emission factor is taken as $0.535 \mathrm{CO}_{2}$ eq. The study assumes that waste composition in SK includes mixed paper, mixed plastics, mixed metals and glass. The "GHG emission saving factor from recycling" shows negative number with value $1.259 \mathrm{CO}_{2}$ eq. Scenario 1 is compared to Baseline scenario because they include "GHG emission from recycling process". Eq. (7) shows that amount of waste treated with recycling process and emission factors are directly proportional to each other. Thus, it can be seen that increasing waste to recycling will increase GHG emission from recycling process. Scenario2 and Baseline1 evaluate GHG

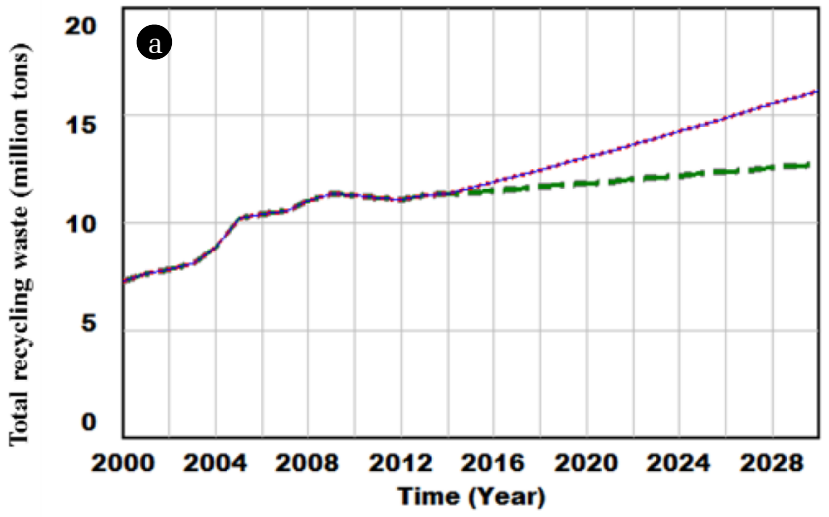

amount of waste to recyling : Scenario2 amount of waste to recyling: Scenariol .............. amount of waste to recyling : Baseline ---------

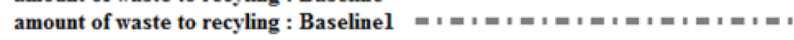

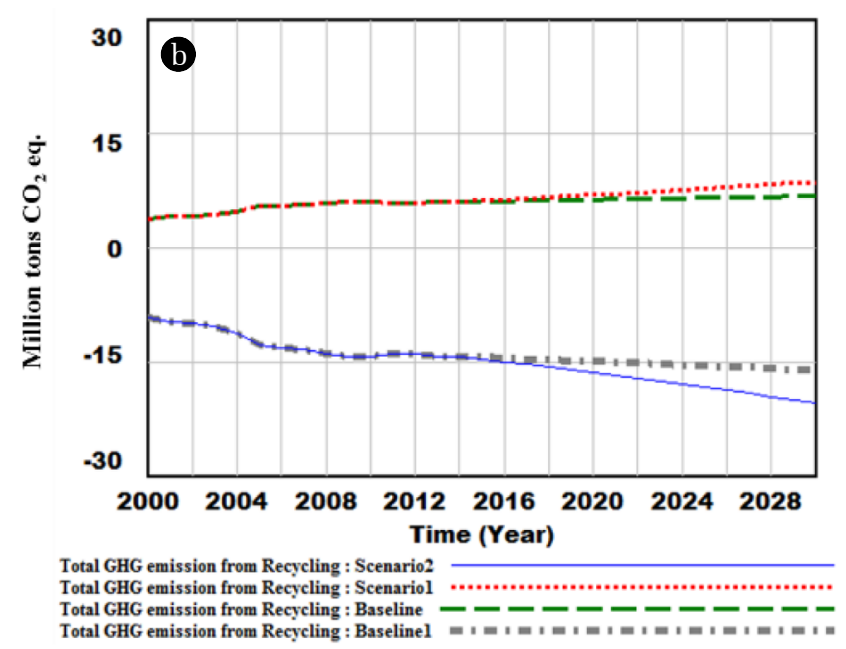

Fig. 6. Total recycling waste and total GHG emission from recycling process in SK (2000 to 2030). 
savings from recycling by using "GHG emission factor from recycling". Scenario 2 shows more negative value which signifies that there is much emission savings from recycling process when ratio of recycling waste in 2030 is $75 \%$ of total waste.

\subsubsection{Total GHG emission}

Fig. 7 shows total GHG emission from landfill, incineration and recycling and table S1 shows detailed value of GHG emission in four scenarios for South Korea from 2000 to 2030. Indeed, it shows high GHG emission savings with adoption of policy of increasing recycling amount to $75 \%$. In definition, "Zero waste policy" is to increase recycling with minimizing landfill waste to utmost point. The GHG generation from recycling process depends on amount of waste to recycling. Ending up with high recycling rate i.e., $75 \%$ in 2030 , it is observed that GHG emission savings from recycling has higher value than GHG emission generation from recycling process. Therefore, it is clinched to increase recycling of waste to decrease final GHG emission from recycling process. The GHG emission from recycling for Scenario1 in 2030 is found to be $11.59 \mathrm{Mt} \mathrm{CO}_{2}$ eq. The GHG emission from recycling for Scenario 2 is estimated to be $-17.45 \mathrm{Mt} \mathrm{CO}_{2}$ eq.

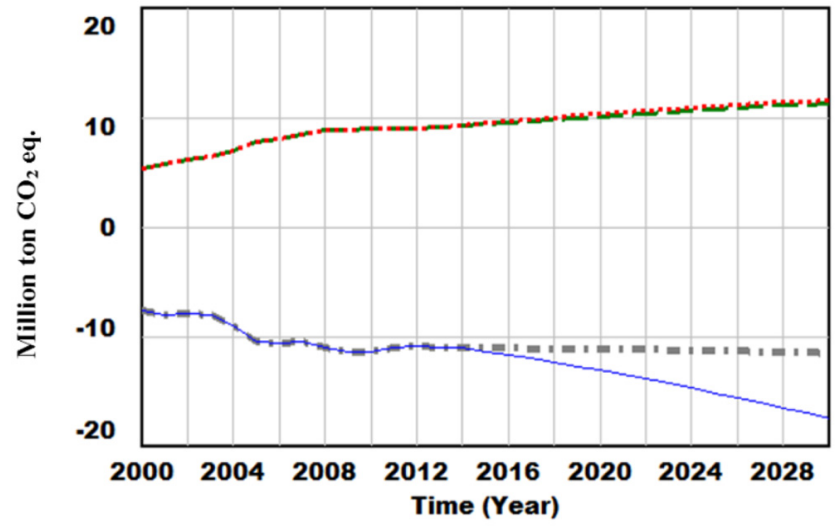

Total GHG emission : Scenario2

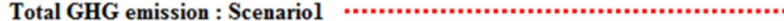

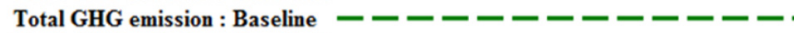

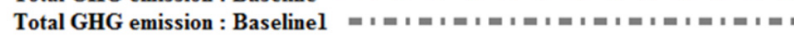

Fig. 7. Total GHG emission from MSW in SK (2000 to 2030).

\section{Conclusions}

The total waste generation is predicted with population and waste generation per capita. The waste generation is found to be increased in future due to increase in the population. The GHG emission from landfill, incineration and recycling depends on the frequency of treating the MSW with the three processes. With simulation of model it has been observed that increasing of recycling waste will reduce the burden on landfill and incineration in future. The more emphasize is on observing behavior of recycling. This study shows that if the ratio of recycling waste will be increased in future (2030) and the landfill waste is decreased with decreasing the ratio of incineration waste as well, the GHG emission from treating the MSW with three processes can be decreased to great extent. This study shows that Scenario2 is the best management option which could be chosen by the Korean government in order to achieve the target of reducing the GHG emission by treating the MSW with three processes by year 2030. Moreover, this study to the best of our knowledge has calculated the GHG emission from landfill, incineration and recycling process for the first time for SK which could be used as reference for future work in terms of finding the GHG emission from MSW.

\section{Acknowledgments}

This project is supported by the "R\&D Center for reduction of Non- $\mathrm{CO}_{2}$ Greenhouse gases (2016001690005)" funded by Korea Ministry of Environment(MOE) as "Global Top Environment R\&D Program".

This work was financially supported by the Korea Ministry of Environment as Waste to Energy-Recycling Human Resource Development Project (YL-WE-17-001).

\section{References}

1. Ministry of Environment Korea. Major policies [Internet]. Available from: http://eng.me.go.kr.

2. Korea Environmental Policy Bulletin. Volume based waste fee system in Korea. Strategy 2006;1:1-16.

3. Park JW. 3R Policies of Korea [Internet]. c 2009. Available from: file://C:/Users/ghye0/Downloads/3R_policies_of_Korea-Mr_ June-Woo_Park.pdf.

4. Sufian MA, Bala BK. Modeling of urban solid waste management system. The case of Dhaka city. Waste Manage. 2007;27:858-868.

5. Talyan V, Dahiya RP, Anand S, Sreekrishnan TR. Quantification of methane emission from municipal solid waste disposal in Delhi. Resour. Conserv. Recycl. 2007;50:240-259.

6. Ministry of Environment. Waste treatment policy and measures in SK background information. 2009;3:1304.

7. Ryu C. Potential of municipal solid waste for renewable energy production and reduction of greenhouse gas emissions in SK. J. Air Waste Manage. Assoc. 2010;60:176-183.

8. Popli K, Sudibya GL, Kim S. A review of solid waste management using system dynamics modeling. Asian J. Energ. Environ. 2009;10:35-52.

9. Thanh NP, Matsui Y. Evaluation of the alternative methods for GHG emission mitigation from municipal solid waste management: case study of o Chi Minh City, Vietnam. Asian J. Energ. Environ. 2009;10:35-52.

10. Sunarto S, Purwanto P, Hadi SP. Quantification of greenhouse gas emissions from municipal solid waste recycling and disposal in Malang city Indonesia. J. Ecol. Eng. 2017;18:74-82.

11. Park WS. Promise of Seoul. Metropolitan government of Seoul [Internet]. c 2016. Available from: https://ccacoalition.org/en/resources/promise-seoul-taking-action-against-climate-change.

12. Wen L, Bai L, Zhang E. System dynamic modeling and scenario simulation on Beijing industrial carbon emissions. Environ. Eng. Res. 2016;21:355-364.

13. Lee S, Paik HS. Korean household waste management and recycling behavior. Build. Environ. 2011;46:1159-1166. 
14. Samah MAA, Manaf LA, Ahsan A, Sulaiman WNA, Agamuthu P, D'Silva JL. Household Solid Waste Composition in Balakong City, Malaysia. Trend and Management. Pol. J. Environ. 2013;22:1807-1816.

15. ATSDR. An overview of environmental health professionals. Chapter2: Landfill gas basics; 2011. p. 3-14.

16. Stănescu R, Bobirică L. Reducing emissions of greenhouse gases from municipal landfills-between theory and reality. Mitigation of methane emissions. Environ. Eng. Manage. J. 2013;12: 1669-1678.

17. Pipatti R, Svardal P. Guidelines for national greenhouse gas inventories. Chapter 3: Solid Waste Disposal Waste. IPCC; 2006.

18. Jung S. National Inventory GHG Report of Korea. Seoul: Greenhouse Gas Inventory Center of Korea; 2014.

19. Johnke B. Emissions from waste incineration. Good Practice Guidelines on Uncertainity Manage. Waste Incineration 2009; 455-468.

20. National Inventory GHG Report of Korea. Seoul: Greenhouse Gas Inventory Center of Korea; 2016.
21. Korea Government. National waste statistic report [Internet]. c2013. Available from: http://eng.me.go.kr.

22. Turner DA, Williams ID, Kemp S. Greenhouse gas emission factors for recycling of source-segregated waste materials. Resour. Conserv. Recycl. 2015;105:186-197.

23. Zlatanovic D. System dynmaics models in management problems solving. Econ. Horiz. 2012;14:25-38.

24. Korea S. Population trends and projections of the world and Korea. 2015;13-15.

25. Silpa K. What a Waste 2.0: A global snapshot of solid waste management to 2050. World Bank; 2017.

26. Pipatti R, Svardal P. Guidelines for national greenhouse gas inventories. Chapter 3: Solid Waste Disposal Waste. IPCC; 2006.

27. Ezechi EH, Nwabuko CG, Enyinnaya O, Babington CJ. Municipal solid waste management in Aba, Nigeria: Challenges and prospects. Environ. Eng. Res. 2017;22:231-236.

28. Kim KY, Kim YJ. Volume-based waste fee system in Korea. 2012:1-132. 